Revista Iberoamericana, Vol. LXVII, Núm. 197, Octubre-Diciembre 2001, 671-685

\title{
LA CONSTRUCCIÓN DISCURSIVA DE LOS PROBLEMAS GLOBALES. EL INTERCULTURALISMO: \\ RESIDUOS, COMMODITIES Y SEUDOFUSIONES ${ }^{1}$
}

\author{
POR \\ AníBAl Ford \\ Universidad de Buenos Aires
}

La elaboración de agendas de problemas globales no es nueva. ${ }^{2}$ Pero ha ido variando con la historia. Las actuales pueden remontarse a las discusiones surgidas de Bretton Woods, el Club de Roma, la discusión sobre los “globals problems”, la crisis del ‘73 y han tenido sus conflictos — como toda imposición de una clasificación y jerarquización- en la política, en la sociedad civil y el tercer sector, en el periodismo y en las Naciones Unidas (es el caso del PNUD). ${ }^{3}$ También en grupos contestatarios, opuestos a la forma en que la globalización neoliberal está organizando el mundo o en las diversas críticas a la supuesta “aldea global”. Lo cierto es que pasada la exacerbación posmodernista no es difícil hoy delinear una agenda de macro problemas (o "macro-relatos") que caracterizan al globo: la creciente brecha entre riqueza y pobreza, las diferentes formas de desocupación o subocupación, la desestructuración de la familia, el rol y la situación de la mujer, las crecientes migraciones documentadas o indocumentadas, la desregulación de la salud, la educación y la asistencia social, el crecimiento de la violencia y la fragmentación de las ciudades, la crisis de los sistemas educativos en los países subdesarrollados, la relación de las nuevas tecnologías con un amplio espectro que va de la aceleración de los juegos financieros a la pérdida de la privacidad, la sociedad de control o de vigilancia, el efecto de las deudas externas en los países pobres, etc.

Desde el punto de vista político y social se puede afirmar que estos problemas no ingresaron fácilmente en los medios ni en sus secciones clásicas de política, economía e internacionales, que funcionan como principales constructores de opinión pública (aunque sí hayan aparecido en las secciones policiales o en la información general de los diarios) así como tampoco ingresan en sus estrategias de establecimiento de agenda (agenda

\footnotetext{
${ }^{1}$ Este artículo forma parte de una investigación mayor en la cual colaboran Mara Leonardi y Francisca Hollmann.

${ }^{2}$ Véase; White, Brian et al. Issues in World Politics, Robertson, Roland, "Mapping the Global Condition”. También Ford, Aníbal y Carolina Vinelli, "La narración de la agenda o las mediaciones de los problemas globales".

${ }^{3}$ Nos referimos al informe que edita anualmente el Proyecto de las Naciones Unidas para el Desarrollo.
} 
setting). ${ }^{4}$ La inscripción de esta agenda, si bien tiene antecedentes, se va a dar en forma más fluida (y por sus valores de noticiabilidad) recién a partir de las protestas que se fueron produciendo en diversas reuniones de los grupos que manejan la economía, los mercados y las finanzas internacionales. Me refiero a la serie de críticas y acciones que comenzaron con la manifestación de diversos grupos contra la Organización Mundial del Comercio (WTU) en Seattle en noviembre de 1999 y que luego se reprodujeron en Washington en marzo de 2000, en contra del Fondo Monetario Internacional y el Banco Mundial y — de manera más indirecta - frente a las propuestas que el G-8 realizó en Okinawa en julio de 2000. Meses después lo que hasta ese momento había constituido protestas de grupos heterogéneos y ONGs, adquirió un mayor nivel de organización en las acciones que se realizaron en Praga en setiembre de 2000 contra el Banco Mundial y el F.M.I y, más recientemente, en Davos (sede del World Economic Forum) ${ }^{5}$ en enero de $2001 .^{6}$ Paralelamente al Foro Económico Mundial los grupos “antiglobalización” organizaron en Porto Alegre un Foro Social Mundial del cual participaron casi 15.000 personas integrantes de diferentes ONG's e instituciones y donde se desarrollaron 400 talleres, todo esto organizado bajo una agenda sistemática de discusión sobre la crítica situación actual y bajo el lema "Otro mundo es posible".

Sin embargo la agenda global crítica que señalamos al principio no estuvo totalmente ausente de la producción massmediática de la última década. Estuvo o está presente - de manera muy discutible - a través de otros canales discursivos: como commodities de la industria cultural tanto en el caso del cine como de la televisión; como dispositivos de impacto en la publicidad; como carne de "caso" o flash de "color" en el periodismo gráfico y como soporte de la TV verdad (de la trash TV a los reality show).

\footnotetext{
${ }^{4}$ En 1972, Donald Shaw y Maxwell McCombs plantearon la hipótesis de agenda setting (establecimiento de agenda) para estudiar la capacidad que tienen los medios de influir en los acontecimientos del público a largo plazo. El público, según los autores, es consciente o ignora ciertos elementos específicos de los escenarios públicos como consecuencia de la atención u omisión que le prestan los medios. Existe, según esta hipótesis, una relación directa y causal entre la agenda de los medios y la agenda de la opinión pública ya que los medios no sólo indican sobre qué se debe pensar sino cómo se debe pensar sobre esos temas (Mc Combs et al. 1999).

${ }^{5}$ World Economic Forum existe desde 1971. Se reúne anualmente en Davos, Suiza, y de este encuentro participan alrededor de 1000 líderes de negocios, 250 líderes políticos, 250 expertos académicos y 250 líderes de los medios de comunicación. La reunión tiene como objetivo dar forma a la agenda global. En conjunto, estas personas definen los principales temas (issues) en materia económica, política y social de manera orientada a la acción (véase www.worldeconomicforum.org). ${ }^{6}$ Posteriormente a la redacción de este artículo se produjeron otras manifestaciones contra la globalización: la de Québec, durante la Cumbre de las Américas (del 20 al 22 de abril de 2001); la de Gotemburgo durante la reunión de la Unión Europea (en mayo de 2001); la de Barcelona, a raíz de la frustrada reunión del Banco Mundial (18 de junio de 2001); la manifestación de Génova durante la Cumbre del G8 (del 15 al 22 de julio de 2001) y la reciente manifestación en Washington en contra del BM y el FMI y por la Paz (del 30 de setiembre al 4 de octubre de 2001).

${ }^{7}$ El Foro Social Mundial se articuló sobre cuatro ejes de discusión: 1. Producción de riqueza y reproducción social, 2. El acceso a las riquezas y la sustentabilidad, 3. La afirmación de la Sociedad Civil y de los espacios públicos y 4. Poder político y ética en la nueva sociedad (véase www.forumsocialmundial.com.br).
} 
Decimos que esta agenda ingresa de manera "discutible" porque estamos ante un proceso típico de la sociocultura contemporánea: el traslado de la información sobre problemas críticos. Los géneros clásicos destinados a profundizar la discusión y estructurar el debate público dejaron su lugar de soporte y pasaron a ocuparlo géneros, como los que ya señalamos, cuya función es otra-el caso de la publicidad-o que, por su carga narrativa, ingresan más en el ámbito del imaginario social que en el de la opinión pública. Esto es lo que ha dado nacimiento al concepto y al fenómeno del "infoentretenimiento". ${ }^{8}$ Si bien esta relación entre información y entretenimiento se dio siempre, nos referimos a un cambio cualitativo en los sistemas de información y sus formatos comunicacionales y discursivos. ${ }^{9}$

Pero para ingresar en estas mediaciones y en los géneros a través de los cuales nos informamos sobre el mundo y sus problemas, vale detenernos rápidamente en algunos datos básicos que contextualizan estos procesos. Ellos son:

- el desplazamiento de las industrias de lo simbólico o de los flujos simbólicos (telecomunicaciones, informática, industrias culturales) hacia el centro del producto bruto de los países más desarrollados, especialmente los Estados Unidos ${ }^{10}$

- el acelerado proceso de la convergencia y de las megafusiones que ha agrupado, por ejemplo, a empresas de información con empresas de entretenimiento, ${ }^{11}$ y que cada vez se concentra más aunque tenga variaciones regionales, o "globales”, como es el caso de MTV de Viacom, reciente compradora de la vieja cadena CBS.

Una de las hipótesis, manejada por diversos analistas, es que las causas -sinergía mediante- del desarrollo del infoentretenimineto, así como de la caída de los géneros de información, se debe al proceso por el cual, luego del final de la guerra fría, las noticias duras dejaron de ser importantes o amenazantes (Ford y Contreras, “Memorias abandonadas o las brechas infocomunicacionales”). Pero esta hipótesis no deja de tener una carga etnocéntrica si consideramos que deja de lado algunos datos crueles de la "aldea global” como que en 1998 hubo 48 conflictos bélicos, o que según un informe del Banco Mundial actualmente hay 1200 millones de personas en el mundo que viven con menos de 1 dólar

\footnotetext{
8 “cóctel de información y entretenimiento, de temas pesados e intrascendentes, banales, escandalosos o macabros, de argumentación y de narración, de tragedias sociales comunicadas en tiempo de swing o clip o narradas como películas de acción...” ( Ford, "La sinergía de los discursos” 95).

${ }^{9}$ Esto no descalifica el complejo concepto de entretenimiento sino sus diversas formas de ingreso en la información tanto como tópico así como retórica.

${ }^{10}$ Según declara el Informe del PNUD 1999 sólo en el sector de las telecomunicaciones las diez empresas más importantes concentran el 86\% de la economía del rubro.

${ }^{11}$ Constituye un buen ejemplo de ambos puntos la discutida y enredada compra de Time Warner por America Online. The Wall Street Journal interactivo anunciaba el 10 de enero de 2000: "America Online, el mayor proveedor mundial de acceso a Internet y el gigante de los medios de radiodifusión y espectáculos Time Warner anunciaron el lunes una fusión que crearía una compañía valorada en US\$350.000 millones”. Es decir, más del doble de la deuda externa argentina y más que todo lo producido en la Argentina en un año. AOL es líder mundial en provisión de servicios de Internet y Time Warner posee la mayor red de cable en Estados Unidos, la cadena de Televisión CNN, la revista Time y un estudio cinematográfico en Hollywood. (Cfr. "Luz verde..." Clarín 15 de diciembre de 2000, 31. Sobre nota de C. Grimmes y P. Spiegel del Financial Times, s.d.).
} 
por día y otros 3000 millones con sólo 2 dólares. La agenda que puntualizamos al principio no es realmente reconfortante.

En relación con esto es importante también señalar:

- el aumento de la masa simbólica a raíz de una mayor relación e interdependencia entre las diferentes socioculturas pero a través de flujos de información (sobre economía, sociocultura,

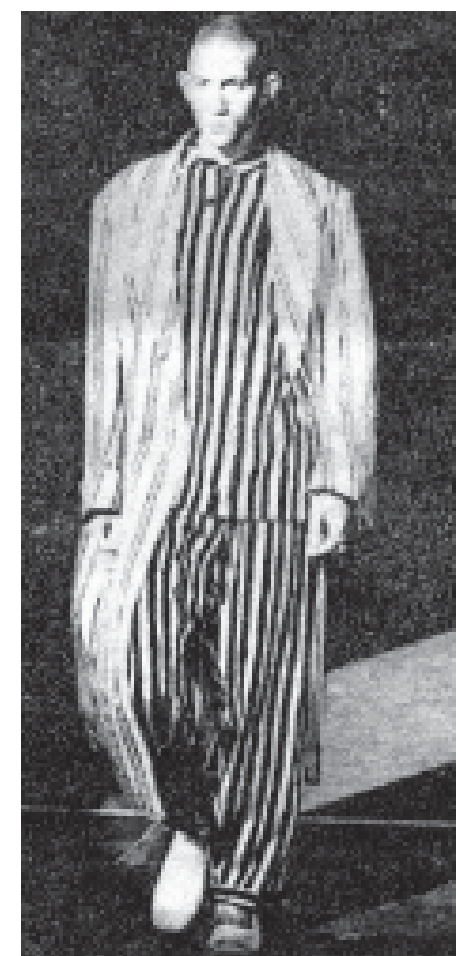

Foto 1. Fotografía del desfile de Comme des Garçon, polémica por los diseños de la japonesa Rei Kawabuco y su relación con los prisioneros de Auschwitz. La Nación, marzo de 1995. historia, etc) totalmente asimétricos;

- las desigualdades infocomunicacionales a nivel de equipamiento e infraestructura (un treinta por ciento de la humanidad no tiene luz eléctrica).

Todo lo que señalamos implica poner en contacto los desplazamientos discursivos en la información sobre problemas críticos con los cambios en los sistemas de producción (Klinenberg, Los periodistas 7).

Este marco es indispensable para analizar el objeto de este trabajo: el mayor peso del intercambio cultural cuyo origen va del crecimiento del turismo ${ }^{12}$ y la globalización de la economía a las migraciones pobres - de documentados e indocumentados-y sus diferentes resultados: multiculturalismo (muchas veces exacerbado), discriminaciones, racismo, ciudadanía de segunda, “cuarto mundo”, etc.

En este marco hay que tener en cuenta que en una sociedad, o en una sociocultura, donde la "racionalidad" del consumo o del mercado avanza con estrategias globales y hegemónicas desaparecen no sólo límites y restricciones sino ordenamientos que se consideran elementales para el funcionamiento de la democracia. De ahí la generación, por ejemplo, en la publicidad, del impacto de marca que juega con la representación y la cultura de "los otros" o que utiliza los problemas globales señalados al principio como dispositivos de efecto o commodities.

El hecho de que en algunos casos haya reacciones de la ciudadanía ante este fenómeno (como sucedió con Benetton durante la campaña realizada con los condenados a muerte, o con Comme des Garçon que hizo un desfile de modas con el "look" de Auchswitz, ${ }^{13}$ o con Diesel que utilizó para promocionar sus jeans un sistema de tortura muy

${ }^{12}$ Con respecto al turismo vale señalar que en 1950 viajaron en todo el planeta 25 millones de personas, en el 2000 lo harán 700 y para el 2020 se calculan 1600 (Gobbi, Mercosur y turismo). ${ }^{13} \mathrm{El}$ “look” se caracterizó por modelos flacas, demacradas, ojerosas, vestidas con rayas horizontales y los números identificatorios que caracterizaban a los uniformes de los campos de concentración nazis (Aulet). 
utilizado por la última dictadura en la Argentina) ${ }^{14}$ (Fотоs 1y 2) no implica que gran parte de estos mecanismos de “comercialización de los derechos humanos” (Ferguson, "El interculturalismo global”) o de transformación en commodities de las agendas que figuraron en algunos de los informes del PNUD ${ }^{15}$ (por ejemplo los índices del "Perfil de sufrimiento humano" $\mathrm{y}$ “Debilitamiento de la trama social” que focalizaban principalmente en el crecimiento de diversas formas de violencia y desestructuración en los países ricos o desarrollados, o en los cuadros

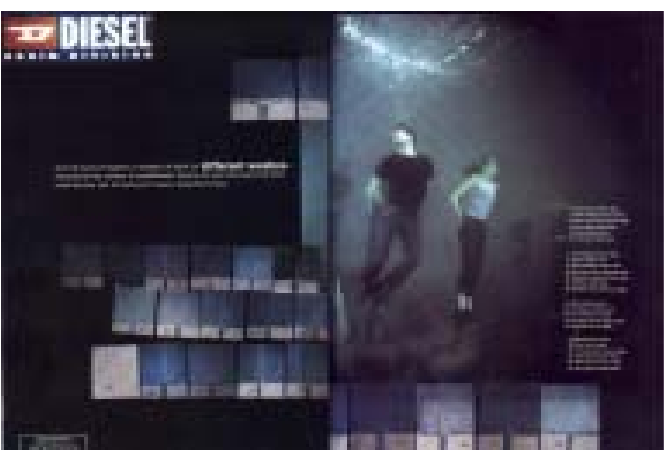

Foto 2. Publicidad de Diesel reproducida en la revista Colors. de "Perfil de privación humana"16 que informaban sobre la falta de acceso a la salud, al agua potable, al saneamiento, la alfabetización, la nutrición y los índices de mortalidad infantil) no sea una característica de la cultura contemporánea. O por lo menos una fuerte tendencia.

Ahora bien, sea cual fuere el ángulo que elijamos: multiculturalismo, interculturalismo o interculturalidad; discriminación y racismo o el estudio de identidad "con o sin la construcción del otro”, el flujo intercultural se ha activado fuertemente. ${ }^{17}$ Las causas son variadas y tanto factuales como simbólicas: el turismo que siempre funciona asimétricamente con las culturas que explora; las migraciones documentadas o indocumentadas producidas fundamentalmente por la brecha entre riqueza y pobreza (aunque también por razones políticas o religiosas) y que muchas veces producen un "doble vínculo" con las culturas receptoras que por un lado necesitan mano de obra "sucia y barata" pero por otro lado desarrollan concepciones y comportamientos racistas; el arrastre del comercio internacional y de la relocalización de las zonas de producción; el aumento en la masa televisiva (ficcional, documental o en clave de entretenimiento), en la publicidad, en las "escrituras de la calle”, de las referencias a otras culturas. También la industria del cable que vista

\footnotetext{
${ }^{14}$ Nos referimos al lanzamiento al mar de jóvenes militantes con una piedra atada a sus piernas. ${ }^{15}$ Informe sobre Desarrollo Humano 1996, publicado por el Programa de las Naciones Unidas para el Desarrollo (PNUD).

${ }^{16}$ En el PNUD 1997 y 1998 este cuadro cambió por “Tendencias de Desarrollo humano” y "Disparidades Sur-Norte".

17 "A fines del siglo pasado, la mayoría de la gente vivía en pueblos y no se hubiera encontrado con un extranjero de una cultura remota en toda su vida. Hoy, a fines de este siglo, la mayoría de la gente entra en contacto con personas de otras culturas a diario. Imágenes de otras culturas llenan las pantallas de la televisión y del cine, y en sus lugares de trabajo, calles y mercados, la gente encuentra comerciantes, migrantes, viajeros y refugiados constantemente, en especial en las ciudades. En el espacio de cien años, la interacción cultural en el mundo ha crecido dramáticamente” (Unesco 1998, 15).
} 
internacionalmente es muy poderosa. ${ }^{18}$ Por último, los diversos intercambios que produce Internet que puede agrupar tanto a grupos contestatarios enfrentados con la globalización neoliberal como a newsgroups de neto corte racista o a multiculturalismos exacerbados (Ford, La Marca de la Bestia).

Todo esto produce diversos fenómenos en los procesos de elaboración y transmisión simbólica así como en las mediaciones de las agendas “globales”. También en los medios que no han definido cómo ubicar este crecimiento de las relaciones interculturales (o de los otros problemas de la agenda global) en una sección, en un marco específico que instale en forma densa esta problemática en la opinión o el debate públicos. De ahí la constante rotación de estos temas entre las diversas secciones o su aparición en clave, por ejemplo, “de caso” más que de información estructural.

Pero lo importante es que la aparición de la problemática del interculturalismo o de la interculturalidad, muchas veces relacionada con la pobreza, no se da sólo en el periodismo de información en el sentido clásico, o en el documentalismo (donde tendríamos que distinguir sus variables específicas de sus desvíos hacia lo comercial o lo turístico) sino en otros géneros y dispositivos discursivos como es el caso de la publicidad, de la ficción, de los reality shows u otros derivados del infoentretenimiento. En síntesis: la ciudadanía se informa sobre la constitución y el desarrollo de uno de los puntos críticos más importantes de la cultura contemporánea a través de mediaciones discursivas (lingüísticas o audiovisuales) que no pertenecen al campo específico de la información dura y que por lo tanto producen cadenas de sentidos (relacionados con el imaginario, con los estereotipos, con los prejuicios, con los estigmas) muy diferentes a la información de base que es necesaria para la constitución de la opinión pública. ${ }^{19}$

Nos interesan, especialmente en este caso, las mediaciones producidas en países con alto nivel de desarrollo acerca de los países “en vías de desarrollo” o subdesarrollados. Dicho en otros términos: las mediaciones que produce ese $20 \%$ de la humanidad que maneja el $80 \%$ de la economía mundial y que construye una mirada muchas veces discriminatoria sobre el otro "pobre”, “dependiente” o “endeudado”, “marginado”. Los sistemas discursivos a analizar pueden organizarse (aunque se intersecten) en diversos ejes, de los cuales retomaremos tres:

\section{LA REACTIVACIÓN DE LOS RESIDUOS}

Nos referimos a un conjunto de recursos retóricos que aunque anteriores al capitalismo, se intensificaron durante la etapa de expansión de los imperios y son importantes por su valor residual. Estos “Tropos del Imperio”, como fueron llamados por Robert Stam y Ella Shohat (Unthinking Eurocentrism, véase especialmente el capítulo 4 “Tropes of Empire”), nunca dejaron de tamizar peyorativamente la imagen del otro. Constituyen, de alguna

\footnotetext{
${ }^{18}$ Si bien cada país consume en primer lugar la televisión nacional abierta, el cable en su expansión internacional abarca un público mucho mayor.

${ }^{19}$ Lo que Herbert Schiller denomina "Información Socialmente Necesaria”, aquella que necesita el ciudadano para decidir sus acciones políticas, económicas y sociales (véase Information Inequality, “Data Derivation” especialmente el capítulo 3).
} 
manera, una relación intercultural asimétrica que sobre la amplia base del darwinismo social funcionaron ideológicamente naturalizando el dominio y la superioridad "racial” de los dominadores.

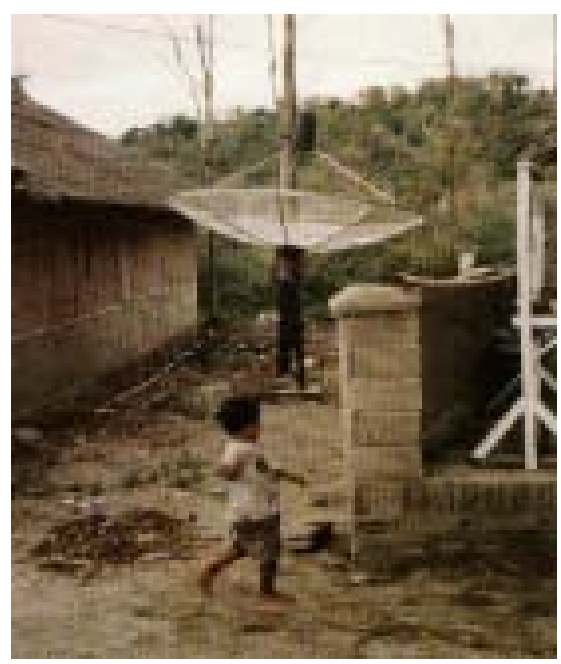

Foto 3. Fotografía documental en Island mentality Owen Hughes, en la revista Multichannel International. Abril de 1999.

Dentro de este marco hay que ver recursos que hoy han vuelto a activarse. La tipología desarrollada por Shohat y Stam incluye los siguientes dispositivos de minusvalorización de los países o de las culturas no-europeas, o no euronorteamericanas: infantilización, animalización, erotización de las tierras vírgenes, fantasías de rapto/rescate, el harén, la odisea del desierto, el locus amoenus, la terra incógnita, los continentes oscuros.

Estos dispositivos que nunca dejaron de estar presentes, como lo vemos en la relación foto/turismo en las publicidades de la década del " 40 (Fото 3) se han reactivado hoy en la "estética" de revistas como Colors $^{20}$ o en las publicidades de los canales documentales como es el caso de Travel Channel. Un ejemplo de esto es la foto "Eliminación/Disposal”, que aparece en el número de Colors correspondiente a enero/febrero 1998, dedicado a la muerte, en especial el capítulo donde se describen las formas de deshacerse de un cadáver (que, además, incluye un artículo sobre los sistemas de eliminación de cuerpos), se muestra a un hindú "pobre" sosteniendo una gran tortuga. El texto que acompaña la foto es trabajado con un sistema de enunciación claramente discriminatorio, cercano al punto de vista del shockdocumental de películas como Mondo Cane:

Un cadáver se descompone cuatro veces más velozmente en el agua que en la tierra. Los peces y los insectos acuáticos (que empiezan su labor mordisqueando los párpados, los labios y las orejas) succionan los tejidos corporales ablandados por el líquido. La materia es abundante (el agua cubre el $75 \%$ del planeta), pero el temor a difundir enfermedades trasmitidas por el agua, como el cólera, hace que pocos gobiernos fomenten la eliminación por el agua. En el Reino Unido, para poder sumergir un cadáver en el mar, se debe certificar que está libre de infecciones y sustancias químicas de embalsamado y hundirlo en zonas especiales (por lo general, las mismas donde se vierten desechos industriales). Los veteranos de la marina y la guardia costera estadounidense pueden ser sepultados en el mar, aunque en ataúdes lastrados agujereados que se entierran a una profundidad mínima de $183 \mathrm{~m}$. En la India, sin embargo, la práctica es tan corriente (cada año se tiran

\footnotetext{
${ }^{20}$ Revista editada por Mondadori y patrocinada por Benetton.
} 
al Ganges unos 3.000 cuerpos y 1.800 toneladas de restos humanos parcialmente quemados) que el gobierno tuvo que idear un ingenioso plan de higiene. Desgraciadamente, los ribereños ya se han comido las 28.820 tortugas criadas para alimentarse con la carne en descomposición.

Este tipo de aproximación al otro ampliamente desarrollada hoy — por ejemplo en canales documentales - puede muchas veces adoptar otro dispositivo: como poner al exotismo y al pintoresquismo en relación con la “modernidad”, en clave de occidentalización, como sucede en la tapa del número de la revista National Geographic Magazine (agosto de 1999) dedicado a la "cultura global”. (Fото 4)

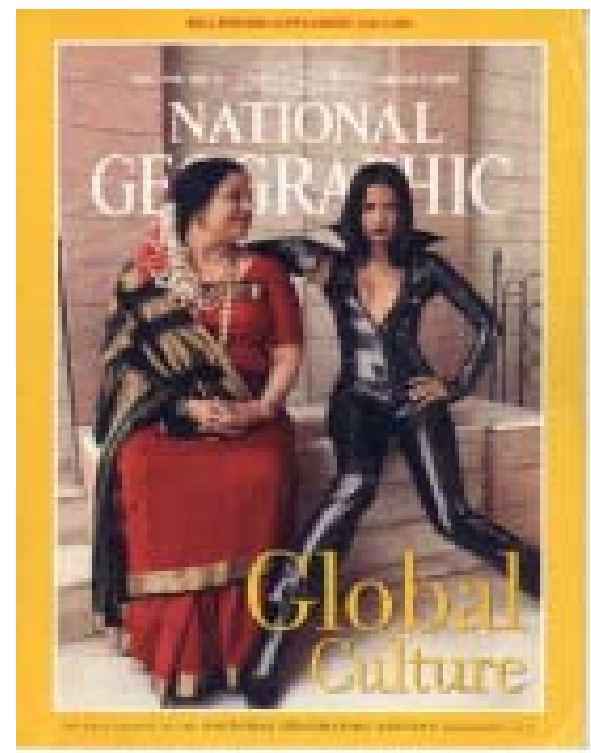

Foto 4. Portada de la revista National Geographic 196/2 (agosto 1999).

\section{LA DESGRACIA COMO COMMODITY}

Así como antes dimos ejemplos con respecto a la relación entre derechos humanos y su utilización en discursos tan ajenos como la publicidad o la moda al hablar de Diesel, de Comme des Garçons, de Benetton, también en otros lugares hemos desarrollado cómo los "Indices de sufrimiento" se transforman en materia prima de la industria cultural y de la publicidad. Un ejemplo: violaciones, homicidios, accidentes, diferencias entre ricos y pobres, desocupación y delincuencia juvenil, delitos relacionados con las drogas, suicidios. Este listado no describe la agenda del periodismo sensacionalista, ni la de las secciones policiales de los diarios, ni los temas de la cartelera masiva del cine o del vídeo, sino 


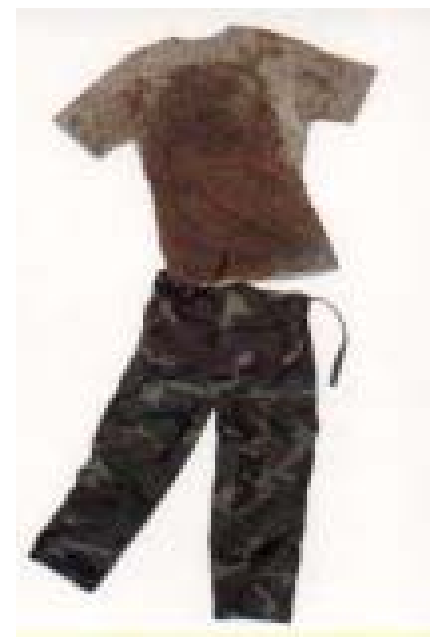

Foto 5. Publicidad de Benetton.

algunas de las variables que utiliza o utilizó el PNUD en 1996 en su "Informe sobre Desarrollo Humano" en sus índices referidos al "Perfil del sufrimiento humano" y al "Debilitamiento de la trama social” (Informe sobre Desarrollo Humano 1996).

Esta aparición del sufrimiento o de lo trágico como dato duro, fuera del pietismo, la beneficencia, el amarillismo o las abstracciones de las "necesidades básicas" insatisfechas, marca nuestra época. A los medidores de la contaminación hubo que agregar los medidores de la crueldad. Aquí tenemos que hacer una observación: estos índices se corresponden más con los países de cierto nivel de desarrollo. En cambio, los índices de privación forman parte (salvo algún flash esporádico o un documental) de la agenda muda de la información internacional. Es que son los datos sobre aquellos que, de manera creciente, quedaron y van quedando afuera, o del otro lado del New Order. Aquellos que están del otro lado de la vidriera, mirando a veces con un televisor cada cincuenta habitantes, los lujos de la sociedad del hipercosumo y la hipertecnología.

Pero lo que interesa es esta coincidencia entre los cuadros más críticos del PNUD, que nadie podría calificar de "amarillos”, con temas y géneros que aparecen no sólo en el ámbito de la información sino en otros campos de comunicación. Son procesados, a veces tratados con respeto y otras de manera light y crapulosa por la industria cultural, el cine, las series y documentales televisivos, los talkshows y otras formas de la televerdad — trash tv incluida - y hasta clips y publicidades. Ahí nos vamos a encontrar frecuentemente con

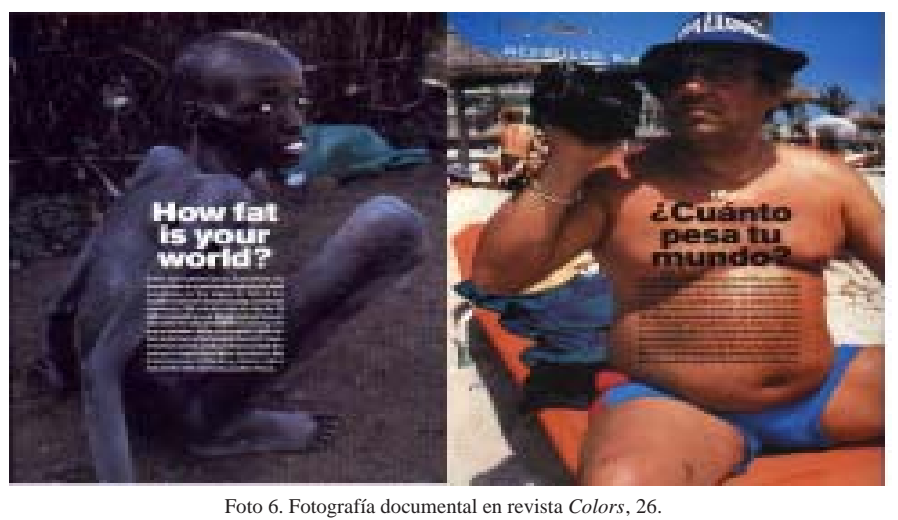

Foto 6. Fotografía documental en revista Colors, 26. 
temas como la discriminación y el racismo, los diversos tipos de violencia, el desempleo y el desamparo social, las ciudades fragmentadas, las migraciones desesperadas y otros temas críticos de la sociocultura de fin de siglo.

Los datos duros, crueles, límites, han pasado a ser —y esto parece conformar una tendencia en crecimiento - materia de géneros "busca ratings" y de la publicidad de construcción de marca por impacto. (FOTO 5)

Estos dispositivos discursivos, muchas veces ponen en relación estos temas con la problemática intercultural que estamos tratando e incluso relacionando interculturalismo y pobreza. (ғото 6)

Si tomamos por ejemplo la visión de Coca Cola, tanto a escala documental (no empresarial) o publicitario (empresarial) vamos a ver que como parte de su estrategia global integra el inter o el multiculturalismo; (FОто 7) o también puede integrar los ámbitos de pobreza, como sucede en el spot referido al campeonato mundial de fútbol donde chicos descalzos juegan a la pelota en un potrero o baldío mientras en el fondo se ve un deteriorado cartel de Coca Cola. Este tipo de temática es muy semejante a la reconstruida en imágenes documentales como las de la revista National Geographic Magazine. (FOTO 8)

El interculturalismo y la pobreza también van a estar expresados en algunas famosas películas realizadas con la estética New Age como son las películas de Godfrey Reggio: Powaqqatsi y Koyaansqatsi donde la denuncia muchas veces está relacionada con una estética de la pobreza que construye un enunciatario correspondiente con la cultura de los países más desarrollados y cercano a las formas de manifestación de instituciones del tercer sector u Organizaciones No Gubernamentales. Tal puede ser también el caso de aquellos anunciantes que ingresan en la publicidad que acompañan los informativos de la CNN.

Si bien Benetton constituye un ejemplo paradigmático de utilización de los diversos datos crueles de nuestra sociedad (según el site de esta empresa en Internet los temas o problemas presentes en sus publicidades son: el SIDA y el sexo seguro; las culturas y

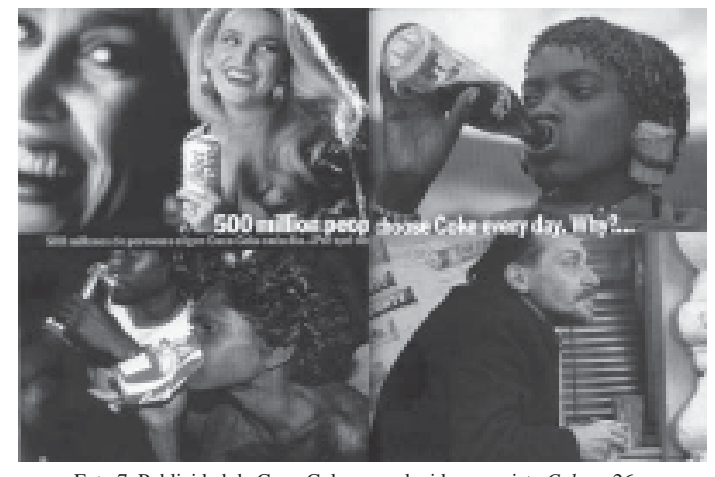

Foto 7. Publicidad de Coca-Cola, reproducida en revista Colors, 26.

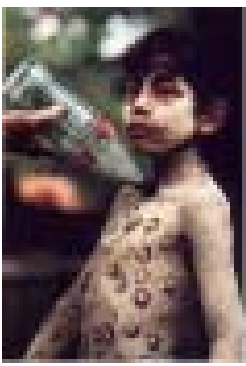

Foto 8. Fotografía documental de una ceremonia indígena en México, en la revista National Geographic 2 (1999). 
formas de vida; el humanitarismo; la paz y la guerra; la raza y la realidad (www.benetton.com) en función de impacto publicitario, nos interesa particularmente su estrategia plural o multiculturalista, desarrollada a partir del diseño textil de "United Colors of Benetton". Lo que algunos han llamado el "síndrome Benetton".

Las invenciones de Tibor Kalman (véase Hall y Beirut, Tibor Kalman: Perverse Optimist) se transforman en una estrategia publicitaria ya en manos de Oliverio Toscani que teoriza sobre la publicidad dándole un valor insólito en la formación de la opinión pública: “La publicidad es la más rica y poderosa forma de comunicación en el mundo. Necesitamos tener imágenes que le hagan a la gente pensar y discutir” (www.benetton.com julio 1998). A pesar de que la publicidad metacomunica con suficiente claridad que su objetivo es vender.

Así como en Estados Unidos surgió, tras el fin de la guerra fría, una tendencia multicultural: el melting pot o el Pluribus in unum que se refleja en el CD-Rom del Time de esa etapa (Time Almanac 1994). La visión multicultural o pluricultural de Benetton va a dar pie al ocultamiento de mayores conflictos que comienzan a producirse y a un juego particular con las relaciones interétnicas y el resto de los problemas globales. En la relación impera la armonía cuando se trata de publicidad, aunque trabaja de manera diferente en la revista Colors donde cruza la visión exótica con la mirada pietista “New Age”. (ғото 9)

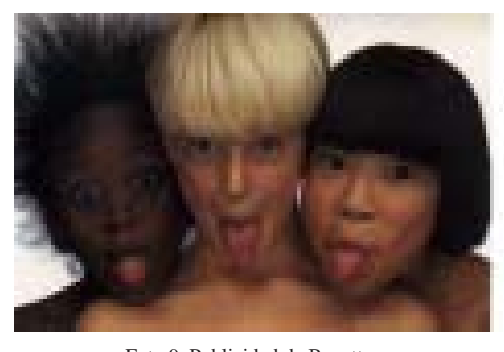

Foto 9. Publicidad de Benetton

La utilización de cualquier recurso, por cruel que sea, para generar impacto publicitario, la mostración de todo en diversas claves de las miserias que conviven en la aldea global señala un proceso de "destape" que no podemos dejar de relacionar con el hecho de que la información estadística crítica ya no es exclusividad de publicaciones políticas contestatarias sino que también aparece en las propias estadísticas del Banco Mundial, como sucede con el Informe Mundial de Pobreza.

\section{LA SEUDOFUSIÓN DE TRADICIÓN Y MODERNIDAD, DE DESARROLLO Y SUBDESARROLO}

En la revista Television Latin America correspondiente a enero de 2001 hay una doble portada en la cual se ven las ruinas de Machu Picchu rodeadas por una ciudad hiperfuturista. El montaje genera, simbólicamente, un nuevo tipo de “parque temático” definido no por 
el traslado o la reproducción sino por su encapsulamiento en la ciudad inteligente del futuro.

Más allá de la inscripción de este montaje en una tópica del diseño contemporáneo o de fantasía "new age” interesa esta fusión entre "tradición”, subdesarrollo, culturas indígenas/ modernidad, futuro tecno. Un recurso que comienza a ser recurrente y repetido y que tiene relación con los diversos intentos tecnológicos de bridging the divides, de alguna manera emparentando diferencias u ocultando la brecha entre riqueza y pobreza, culturas hegemónicas y culturas en desplazamiento o desaparición. (Fото 10)

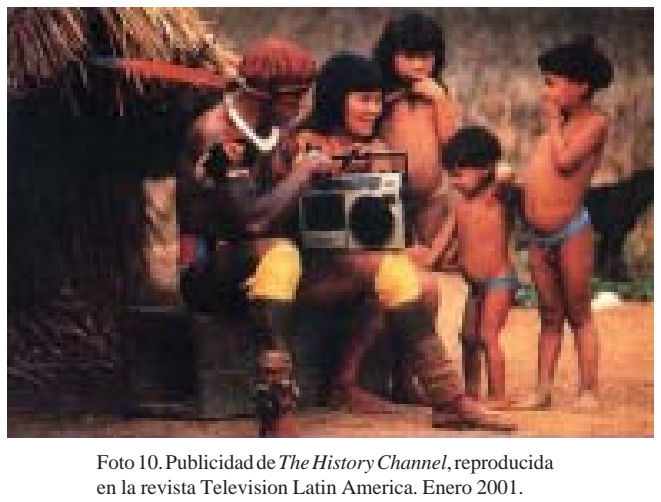

Dijimos que los montajes biculturales de este tipo son frecuentes y que implican una hermandad que no se condice con los datos duros que mencionamos al principio. En este sentido vale recordar que en la reunión que el Grupo de los 8 mantuvo en Okinawa (Japón) en julio de 2000, la problemática de la "Brecha Digital” pasó a ser el centro de la cuestión y se la propuso como una "Oportunidad Digital”, que como la larga lista de utopías comunicacionales — de McLuhan y la cibernética a Bill Gates y Negroponte — se propone como solución primera para resolver los grandes problemas que aquejan a la humanidad, computarizar el mundo. Aunque ahora desde un lugar privilegiado en la economía mundial (véase Ford, “El G-8, Okinawa y la digital Divide”).

A pesar de las críticas y de las observaciones a una puesta en práctica no adecuada de las nuevas tecnologías en países pobres, esta nueva utopía comunicacional y comercial continúa manteniendo su propuesta como lo vemos en el spot “Are you ready?” de Cisco Systems.

Es decir, la brecha puede ser elaborada de diversas maneras, lo cual demuestra que hay una zona verdaderamente confusa entre las fotos con una intencionalidad de denuncia o de exploración estética (o de ambas a la vez como sucede con la obra de fotógrafo Sebastián Salgado) que ponen en escena la coexistencia de dos mundos muy disímiles en su situación socioeconómica (Fото 11) con la utilización del mismo recurso en otros 
géneros como ya lo hemos demostrado. Esta brecha encuentra una de sus salidas en los montajes o bricolages que ejemplificamos, en las secuencias sintagmáticas de corte evolucionista de la publicidad del Discovery Channel (ғото 12), en el juego digital sobre las culturas "tradicionales" o en los efectos siempre fuertes de la ambigüedad. (ғото 13)

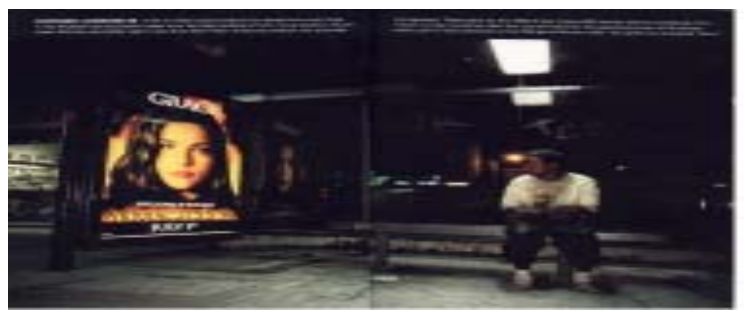

Foto 11. Fotografía documental en "Good move. And cultures changes". Erla Zwingle en National Geographic 2 (agosto 1999).

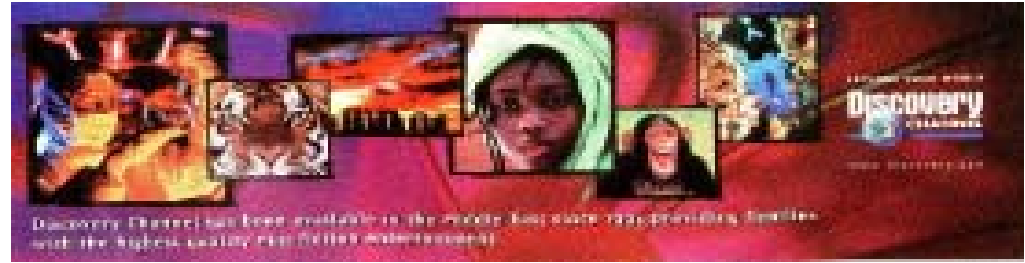

Foto 12. Publicidad de Discovery Channel, reproducida en la revista Multichannel International. Noviembre/diciembre de 1991.

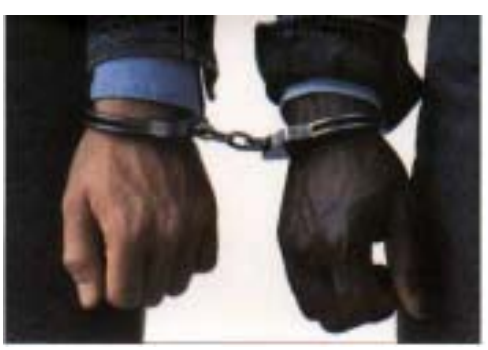

Foto 13. Publicidad de Benetton 
Estas transformaciones discursivas, estas nuevas cargas de mediaciones, estos desvíos de objetivos constructores de la modernidad, la democracia, la opinión publica, forman parte de un proceso de transformación sociocultural en marcha, crítico e incierto. En ellos subyace la estructuración de la sociedad global en clave de mercado y el peso de éstos sobre la producción y circulación de la información y el sentido, pero como no hay sistemas que históricamente cierren, también se puede pensar que estamos ante reciclamientos o transformaciones que como lo señala el slogan de Porto Alegre - “Otro mundo es posible"-reubiquen los deteriorados derechos a la información y la comunicación en función de una opinión pública sólidamente constituida.

BiBLIOGRAFÍA

“Luz Verde para AOL- Time Warner”. Clarín (Buenos Aires, 15 de diciembre de 2000): 31. Sobre nota de C. Grimmes y P. Spiegel del Financial Times (s.d.)

Aulet, María Victoria “Acerca de la moda y sus límites”. La Nación. Suplemento Espectáculos (9 de marzo de 1995): 6.

Colors. A Magazine About the Rest of the World/ Una revista sobre el resto del mundo. “Muerte. Manual de instrucciones/ Death. A User’s Manual”. Milán: Mondadori, 1998. 30-31.

Ferguson, Robert: "El interculturalismo global y los dilemas del universalismo: educando en medios después del 2000”. Diálogos de la comunicación 52 (agosto 1998): 19-30.

Ford, Aníbal. La Marca de la Bestia. Identificación, desigualdades e infoentretenimiento en la sociedad contemporánea. Buenos Aires: Norma, 1999.

"El G-8, Okinawa y la Digital Divide o la utopía comunicacional como sistema de dominio”. Diálogos de la Comunicación 59/60, publicación de FELAFACS (Federación de Facultades Latinoamericanas de Comunicación Social) (octubre 2000): 201-08.

"La sinergia de los discursos o la cultura del infoentretenimiento”. La Marca de la Bestia. Identificación, desigualdades e infoentretenimiento en la sociedad contemporánea. Buenos Aires: Norma, 1999.

y Silvana Contreras: "Memorias abandonadas o las brechas infocomunicacionales". La Marca de la Bestia. Identificación, desigualdades e infoentretenimiento en la sociedad contemporánea. Aníbal Ford, ed. Buenos Aires: Norma, 1999. 115-72. y Carolina Vinelli. "La narración de la agenda o las mediaciones de los problemas globales”. La Marca de la Bestia. Identificación, desigualdades e infoentretenimiento en la sociedad contemporánea. Aníbal Ford, ed. Buenos Aires: Norma, 1999. 1792.

Gobbi, Jorge. "Mercosur y turismo: transformaciones identitarias en el marco del aumento de los flujos turísticos globales y regionales”. Mimeo. Ponencia presentada en las IV Jornadas de investigadores en comunicación. Carrera de Ciencias de la Comunicación, Universidad Nacional de Jujuy, Argentina, agosto 1999.

Hall, Peter y Michael Beirut (eds.). Tibor Kalman: Perverse Optimist. New York: Princeton Architectural Press, 1998. 
Klinenberg, Eric. "Los periodistas 'para todo' del Chicago Tribune”. Le Monde Diplomatique (febrero 1999): 7.

Koyaanisqatsi. Dir. Godfrey Reggio. New Mexico: Institute for Regional Education, 1983.

McCombs, Maxwell y David L. Protess. Agenda Setting. Readings on Media, Public Opinion and Policy Making. New Jersey: Lawrence Erlbaum Associates Publishers, 1991.

Powaqqatsi: Life in Tranformation. Dir. Godfrey Reggio. North Hollywood, CA: Imperial Entertainment Corp., 1990.

Programa de las Naciones Unidas para el Desarrollo (PNUD). Informe sobre el Desarrollo Humano 1996. Madrid: Mundi Prensa, 2000.

Programa de las Naciones Unidas para el Desarrollo (PNUD). Informe sobre el Desarrollo Humano 1996. Madrid: Mundi Prensa, 1998.

Programa de las Naciones Unidas para el Desarrollo (PNUD). Informe sobre el Desarrollo Humano 1996. Madrid: Mundi Prensa, 1996.

Robertson, Roland. "Mapping the Global Condition”. Globalization. Social Theory and Global Culture. Londres: Sage, 1992.

Schiller, Herbert “Data Deprivation”. Information Inequality. New York: Routledge, 1996. 43-58.

Shohat, Ella y Robert Stam. “Tropes of Empire” (Chapter 4) Unthinking Eurocentrism. London: Routledge, 1994. 137-66.

Television Latin America 1 (2001). Miami: Cahners Business Information.

Time Almanac 1990s. Cambridge, MA: Softkey International Inc., 1994.

Unesco. “General Introduction”. World Culture Report. Culture, Creativity and Market. París: Unesco Publishing, 1998.

White, Brian, Richard Little, Micheal Smith. Issues in World Politics. London: Macmillan, 1997.

World Culture Report. Culture, creativity and market. París: Unesco, 1998.

www.benetton.com

www.forumsocialmundial.com.br

www.worldeconomicforum.org 